\title{
Improvement of Fatigue Properties of AZ31B Extruded Magnesium Alloy through Forging
}

\author{
A. Gryguć, S.K. Shaha, S.B Behravesh, H. Jahed, M. Wells \\ University of $W$ aterloo (Department of Mechanical \& Mechatronics Engineering, 200 University Ave W, Waterloo, ON N2L 3G1, \\ $C A N A D A)$ \\ agrygu@uwaterloo.ca, bttps://orcid.org/0000-0003-4138-4859 \\ skumarshaha@uwaterloo.ca, https://orcid.org/0000-0002-1037-0211 \\ sbbehravesh@uwaterloo.ca, bttps://orcid.org/0000-0001-6613-2362 \\ bjabed@uwaterloo.ca, bttps://orcid.org/0000-0002-0270-9254 \\ mawells@uwaterloo.ca, bttps://orcid.org/0000-0001-5789-2773

\section{B. Williams} \\ CanmetMATERIALS(Natural Resources Canada, 183 Longwood Road South, Hamilton, ON L8P 0A1, Canada) \\ bruce.williams@canada.ca, bttps://orcid.org/0000-0003-0088-4638
}

\begin{abstract}
Axial monotonic and load-controlled fatigue tests were performed to investigate the influence of forging at various temperatures and different deformation rates, on both the microstructural and mechanical behaviour of extruded AZ31B magnesium alloy. The obtained microstructural analysis showed that the extruded AZ31B magnesium alloy possesses a bimodal grain structure with strong basal texture. In contrast, once forged, the material showed refined grains and a modified texture. A monotonic yield and ultimate tensile strength of about $223 \mathrm{MPa}$ and $278 \mathrm{MPa}$ were observed for the forged samples showing an increase of $18 \%$, from the as-extruded material. The optimum forging condition was determined to be the coldest of the investigated temperatures, based on the improvement in both monotonic and cyclic properties vs. the as-extruded material. The fractographic analysis of the failure surfaces showed that ductile type fractures occurred in both asextruded and forged samples. However, more dimples and plastic deformation were identified in the fracture surfaces of the forged specimens. A significant improvement of fatigue life was also observed for all of the forged samples, in particular those forged at $400^{\circ} \mathrm{C}$ and $39 \mathrm{~mm} / \mathrm{min}$. Forging improved the fatigue life via a combination of grain refinement and texture modification resulting in improved strength and ductility.
\end{abstract}

KEYwORDs. Magnesium; Forging; Fatigue Characterization; Texture; AZ31B.

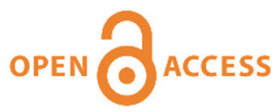

Citation: Gryguć, A., Shaha, S.K., Behravesh, S.B., Jahed, H., Wells, M., Williams B., Improvement of Fatigue Properties of AZ31B Extruded Magnesium Alloy through Forging, Frattura ed Integrità Strutturale, 53 (2020) 152-165.

Received: 27.02 .2020

Accepted: 10.04 .2020

Published: 01.07.2020

Copyright: (C) 2020 This is an open access article under the terms of the CC-BY 4.0, which permits unrestricted use, distribution, and reproduction in any medium, provided the original author and source are credited. 


\section{INTRODUCTION}

here has been a strong impetus towards increasing levels of fuel efficiency and decreasing emissions in the automotive industry throughout the past several decades [1]. Magnesium and its alloys show a very promising future with widespread applicability in fatigue-critical components since they are the lightest structural metal and possess cyclic properties similar to that of the heavier materials which are currently used in industry [2]. However, strong crystallographic texture formed during processing and resultant anisotropic mechanical properties coupled with limited slip systems at low temperature cause poor formability which limits the application of most magnesium alloys. Numerous studies [3-6] have been performed with the aim of weakening the crystallographic texture which reduces the anisotropy in mechanical properties. The most commonly reported mechanism for texture weakening of magnesium alloy is introducing rare earth elements. The addition of $\mathrm{Y}, \mathrm{Nb}, \mathrm{Gd}, \mathrm{Ce}, \mathrm{Ng}$ etc. in magnesium alloys acts to weaken and randomize the texture during deformation processes like extrusion, forging and rolling, which causes a reduction of crystallographic texture intensity due to a more favorable deformation ratio of basal, prismatic and pyramidal slip [4]. Recently, Sarker et al. [3] proposes multidirectional compression as a method for randomizing the texture and reduce the de-twinning activity. Multidirectional forging (MDF) is another processing method which has been recently explored using magnesium alloys by several researchers [7-12] in which the material is compressed at elevated temperature over a number of successive passes incorporating a rotation of the forged material within the forging dies between each pass. This incremental approach towards bulk deformation also acts to weaken the texture, promote grain recrystallization and achieve large total strains. The grain refining effect which MDF has on $\mathrm{Mg}$ alloys can dramatically enhance the strength and ductility of the material, the efficacy of which is highly dependent on the processing conditions, number of passes and particle stimulate nucleation (PSN) propensity of the alloy [8]. This previous work on Mg-RE alloys and MDF [7, 9, 18,10-17] characterized the evolution of the monotonic properties and texture intensity over the duration of subsequent passes of thermomechanical processing, mainly to improve the mechanical properties such as strength and tensile ductility. However, there was limited improvements on bendability which is dominant in forming operations and crash events. The current work focuses on characterizing the fatigue behaviour of forged $\mathrm{Mg}$ alloys for fatigue critical components which is largely unknown in literature. A goal of the current work is to better understand the mechanisms affecting fatigue life of non-rare earth $\mathrm{Mg}$ alloys with appreciable texture, and characterize the structure-properties relationship of uni-axially forged AZ31B Mg.

Although studies regarding the effect of varying processing parameters on the mechanical properties of forged magnesium are available in literature, they are not numerous. Madaj et al [19] investigated the effect which varying the forging parameters had on the AZ $(31,61,91)$ family of $\mathrm{Mg}$ alloys in open-die forging at both hot and warm working temperatures. They determined the optimal temperature window for achieving the desired geometry of near net shape components via dieforging of cast-homogenized AZ31 magnesium to be between $290-345^{\circ} \mathrm{C}$. Kobold et al [20] performed both axial and radial open die forging of extruded AZ80-T5 at rates between $5-20 \mathrm{~mm} / \mathrm{sec}$, and observed no significant difference on the anisotropy of the material flow regardless of the forging direction. They concluded that optimal isothermal forging temperature (from the perspective of achieving maximum forgability) to be $350^{\circ} \mathrm{C}$, and also recommending that this optimum condition tends toward lower temperatures with increasing strain rate as higher than optimal temperatures induced by the heat of deformation can lead to undesirable hot cracking. Kurz et al [21] investigated at various temperatures $\left(180^{\circ} \mathrm{C}\right.$, $240^{\circ} \mathrm{C}$ and $340^{\circ} \mathrm{C}$ ) the behaviour of as-extruded ZK60 and AZ80-F magnesium during closed die forging. They concluded that at higher deformation rates $(300-400 \mathrm{~mm} / \mathrm{sec})$ forging at $240^{\circ} \mathrm{C}$ resulted in the most desirable mechanical properties of those temperatures which were investigated. Furthermore, they observed that increasing the forging temperature decreases the mechanical strength due to grain growth but enhances the elongation due to increased microstructure homogeneity. Miura et al [17], investigated the effect of multi-directional multi-step forging on the mechanical properties of AZ61 alloy, and discovered that the effect that cumulative strain had on grain refinement was pronounced. They observed that with decreasing grain size came increasing levels of microstructure homogeneity and corresponding increases in strength supporting Hall-Petch relation for Mg alloys also observed by [7, 21-23]. More recent studies by Gryguć et al on forged AZ80 Mg [24-25] also highlight the modification of both microstructure and texture in multi-dimensional forging, and the resulting increase in strength and ductility and complex behaviour in the fatigue response.

The focus of state-of-the-art literature surrounding wrought $\mathrm{Mg}$ alloys is on the tension-compression properties and fatigue behavior of cast, extruded and rolled processing techniques. Somekawa et al. [26] studied the fully reversed stress controlled cyclic behaviour in extruded AZ31 Mg alloy with appreciable texture and observed pronounced asymmetry and twinning in the compressive response. Yin et al. [27] was able to connect the salient deformation mode to the morphology of the fracture surface when they found that under strain controlled cyclic testing the stable crack propagation zone is characterized by a lamellar structure resulting from twinning dominated deformation, whereas the final fracture zone has a dimpled 
morphology resulting from slip being dominant. Other studies [28-31] also investigated the effect of sample direction on fatigue crack growth in magnesium alloys. More detailed studies regarding multiaxial cyclic response, failure mechanism and fatigue life modeling also indicate analogous effects of thermomechanical processing on the texture evolution, monotonic and cyclic responses of AZ31B Mg alloy [32-38] and other Mg alloys [39-42].

Despite the previous research mentioned above, the study of the cyclic behavior of forged magnesium, in particular the load-controlled fatigue properties of extruded then forged magnesium alloy is quite limited in the literature. Specifically, although the texture reorientation in $\mathrm{Mg}$ due to forging has been explored previously, it is unclear the processing conditions and strain required to fully recrystallize the microstructure rotate the predominant basal plane in forgings of industrially relevant sizes. Therefore, the aim of this study was to discuss the effect that the thermomechnaical forging conditions have on the microstructure and mechanical properties such as uniaxial tensile and compressive, and cyclic rotating-bending fatigue properties of extruded AZ31B Mg alloy. Finally, identifying the sensitivity of extruded AZ31B Mg alloy to both forging temperature and strain rate will also be explored with the objective of producing desirable properties with good homogeneity.

\begin{tabular}{|c|c|c|c|c|c|c|c|c|c|c|c|}
\hline ID & $\begin{array}{c}\text { Forging Rate } \\
{[\mathrm{mm} / \mathrm{min}]}\end{array}$ & $\begin{array}{l}\text { Temp } \\
{\left[{ }^{\circ} \mathrm{C}\right]}\end{array}$ & $\begin{array}{c}\text { Grain size } \\
{[\mu \mathrm{m}]}\end{array}$ & $\begin{array}{r}\sigma_{Y S} \\
{[\mathrm{M}}\end{array}$ & $\sigma_{\mathrm{UTS}}$ & $\begin{array}{c}\varepsilon_{\mathrm{FAIL}} \\
{[\%]}\end{array}$ & $\mathrm{n}$ & $\mathrm{K}$ & $\sigma_{f}^{\prime}$ & $\mathrm{b}$ & $\begin{array}{c}\sigma_{\mathrm{FAT}} @ 10^{7} \\
{[\mathrm{MPa}]}\end{array}$ \\
\hline Base & As-extruded & - & $32.5 \pm 3.5$ & 189.4 & 235.4 & 17.5 & 0.11 & 330 & 281.4 & -0.048 & 129.8 \\
\hline S1 & 3.9 & 300 & $16.8 \pm 1.9$ & 224.2 & 277.5 & 26.3 & 0.11 & 394 & 346.9 & -0.062 & 127.7 \\
\hline $\mathrm{S} 2 \mathrm{a}$ & 3.9 & 400 & $14.5 \pm 0.8$ & 202.0 & 269.3 & 22.0 & 0.14 & 404 & 260.3 & -0.036 & 145.7 \\
\hline $\mathrm{S} 2 \mathrm{~b}$ & 39 & 400 & $8.8 \pm 0.5$ & 210.6 & 276.7 & 23.4 & 0.12 & 399 & 258.1 & -0.033 & 151.6 \\
\hline $\mathrm{S} 2 \mathrm{c}$ & 390 & 400 & $8.5 \pm 0.2$ & 212.8 & 276.8 & 23.5 & 0.12 & 402 & 315.2 & -0.053 & 134.1 \\
\hline S3 & 3.9 & 450 & $10.7 \pm 0.5$ & 196.9 & 257.2 & 21.0 & 0.12 & 376 & 317.3 & -0.054 & 132.9 \\
\hline
\end{tabular}

Table 1: The relationship between gran size, forging, strength, elongation, hardening, and fatigue parameters of AZ31B alloy forged at various temperatures and rates.

\section{EXPERIMENTAL}

1 he material used in this investigation was commercially available AZ31B magnesium alloy. The material was received from HADCO in the form of an extruded billet of diameter $63.5 \mathrm{~mm}$ in the as-fabricated condition. The forging was conducted at CanmetMATERIALS using AZ31B extruded feedstock of the aforementioned diameter which was cut into $65 \mathrm{~mm}$ lengths. Wong et al. [43] characterized the small-scale compression response of this alloy between 300 and $500{ }^{\circ} \mathrm{C}$ with the strain rate ranging between 0.001 and $1 \mathrm{~s}^{-1}$. The samples were too small to extract subsequent coupons for mechanical testing but this study was used to help eliminate unfavorable forging conditions for the intermediate scale forgings conducted in the current work. All tests were carried out on a 500 Ton hydraulic press with an upper and lower platen (die) which were both flat. The billet and tooling were heated separately to the same temperature of $300^{\circ} \mathrm{C}, 400^{\circ} \mathrm{C}$, and $450^{\circ} \mathrm{C}$. The orientation of the billet to the press was such that the radial direction was along the direction of the press stroke (i.e. direction of forging was coincident to radial direction of the billet). Forging was done at three different deformation rates of 3.9, 39 and $390 \mathrm{~mm} / \mathrm{min}$. It should be noted that each condition will subsequently be referred to as S1, S2a, S2b, S2c and S3 as shown in Table 1. The as-extruded material (Fig. 1a) was coated with graphite lubricant to reduce the friction between the billet and dies. The material was forged from a height of $63.5 \mathrm{~mm}$ to $13 \mathrm{~mm}$ and then air cooled (Fig. 1b). Although the die temperature remained almost constant throughout the test, the billets heat loss to the surrounding air during forging was expected, particularly for the slower forging rate condition. Fig. $1 \mathrm{c}$ and $\mathrm{d}$ shows the orientation for which the metallographic, tensile, compression and fatigue tested specimens were extracted from both the extruded and forged billets. As shown in Fig. 1c, the extruded specimens were extracted from a location which was $\sim 50 \%$ of the radius of the as-extruded billet. All specimens were taken with their longitudinal axis coincident with the extrusion direction of the as-extruded and forged billets as to highlight the effects of texture reorientation. Furthermore, to ensure consistency between the mechanical behaviour of different specimens, all tensile and fatigue specimens were extracted such that the middle of the gauge section coincided with the thru thickness plane of symmetry of the forged sample, as shown in Fig. 1 d. Fig. 2 shows a schematic representation of the temperature history of the billet during the heating, forging and cooling phases for the $400^{\circ} \mathrm{C}$ temperature forgings (S2a, S2b, S2c). The effective strain (imposed by the uniaxial forging step) within the gauge section of the forged samples is in the approximate range of $\sim 125-175 \%$. 
(a)

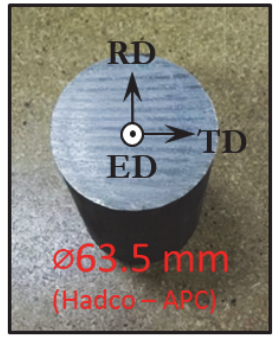

(b)

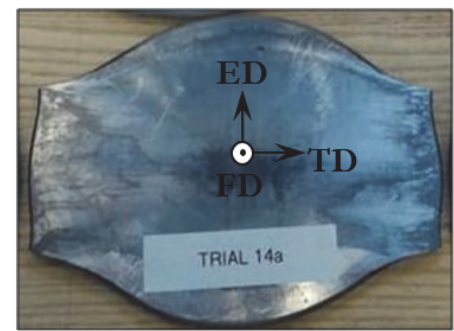

(c)

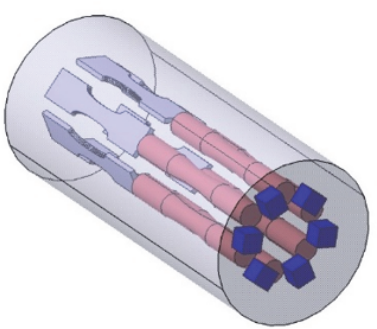

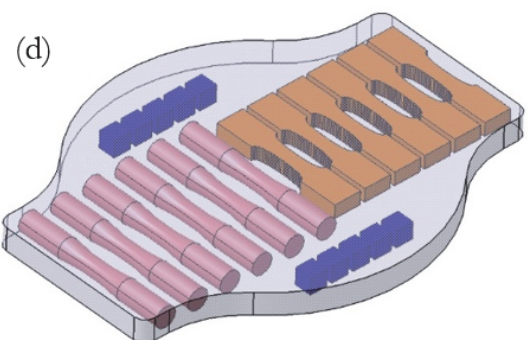

Figure 1: Isometric images of (a) as-extruded billet (b) radially forged sample; and schematic diagram showing the location of tensile and fatigue test sample extraction in (c) as-extruded billet (d) and forged billet.

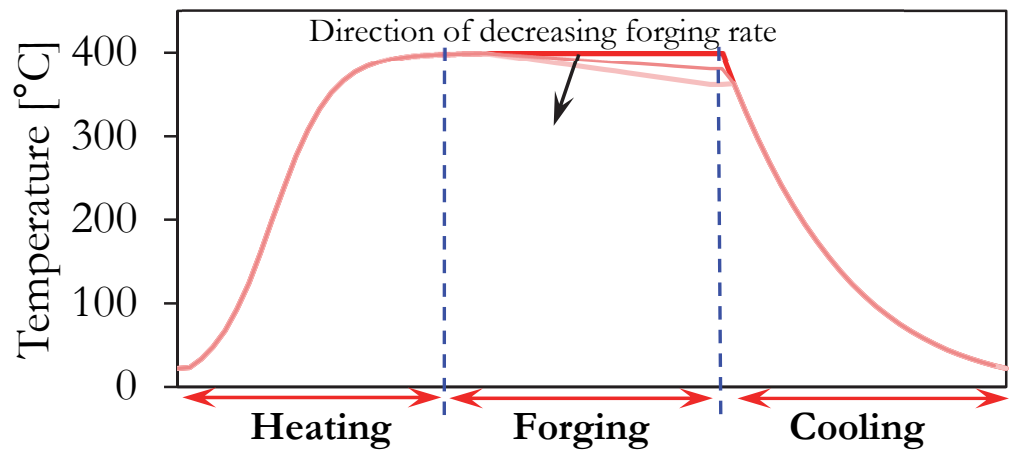

Figure 2: Schematic representation of temperature history for various stages of the processing during forging of the AZ31B extruded magnesium alloy. Different line weights show approximate effect of convective cooling on the slower rate forgings.

\section{RESULTS}

\section{Microstructure and Texture}

7 he as-extruded sample (base) possesses severely bimodal grain structure whose major axis is oriented along the extrusion direction, and surrounded by clusters of smaller grains (Fig. 3a). The calculated average grain size for the as-extruded material is $32.5 \mu \mathrm{m}$ with a significant bi-modal size distribution. As seen in Fig. 4, the forged specimens all exhibited a refinement in grain size, with grain refinement being more pronounced as forging speed increases. In contrast, the forged samples exhibited an average grain size ranging between 8-17 $\mu \mathrm{m}$ (corresponding to a reduction in grain size of between $\sim 48-73 \%$ compared to the as extruded material). The grain morphology in the forged conditions appears to be much more "pancake" like in nature with microstructures ranging from partially recrystallized (S1 and S2a) to fully recrystallized (S2b, S2c). The fully recrystallized grains in the forgings (S2b and S2c) are considered to be the optimal microstructure (of the investigated conditions) based on the more equiaxed and homogeneous grain morphology and considerable grain refinement of $\sim 74 \%$ compared to the as extruded condition. These microstructural observations agree well with those made by other researchers whom investigated multidirectional forging of $\mathrm{Mg}$ alloys [7-10, 44], such that the accumulated strain following the first step of MDF ranges from $50-150 \%$, and the resulting level of grain refinement is $\sim 50 \%$, for a variety of different alloys and processing conditions. Furthermore, they have also observed that the first pass of MDF (which is loosely similar to the style of forging and resulting forged material investigated in this work), yields the largest grain refining effect with each subsequent pass exhibiting diminishing response [10]. The highest temperature forging (S3) exhibited a fully recrystallized grain structure with moderate grain growth (average grain size $\sim 19 \%$ over the optimum 
forging condition S2c.) It should be noted however that the microstructure of the highest forging temperature $\left(450^{\circ} \mathrm{C}\right)$ exhibited further improvement in homogeneity, which was accompanied by a reduction in both tensile and compressive ultimate strength, a trend which directly agrees with findings presented by Kurz et al [21] in AZ80 die forgings.

Figure $3(b, c)$ depicts the calculated pole figures for the basal (0002) and prismatic $(10 \overline{1} 0)$ planes obtained via XRD. There is a strong texture in the as-extruded condition (Fig. 3 b,c) with the c-axis of the hexagonal close-packed (HCP) crystal orientated along the radial direction of the billet. The forged material shows a trend of texture strengthening with temperature, particularly in the basal plane, with its c-axis orientation being coincident with the forging direction (radial direction).

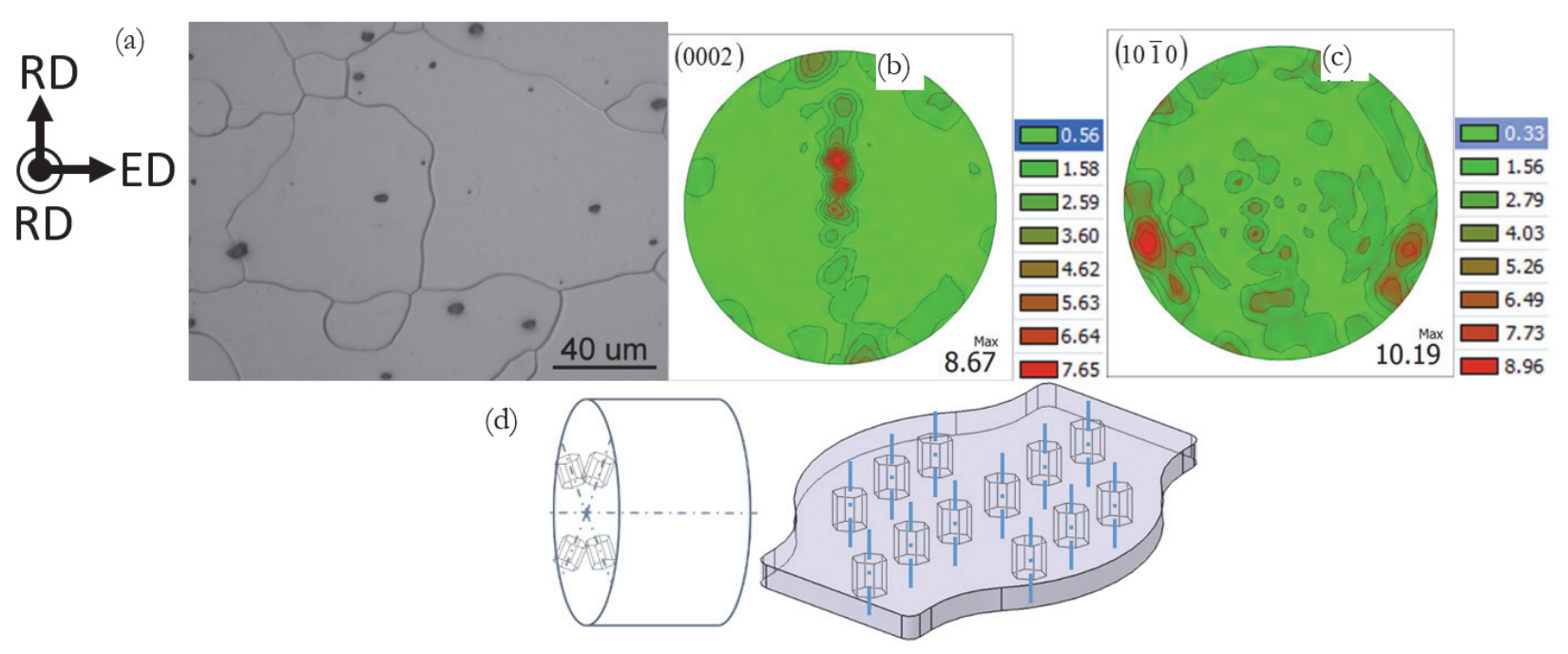

Figure 3: (a) Initial microstructure and (b) (0002) and (c) (1010) pole figures of the as extruded AZ31B magnesium alloy (d) the schematic diagram showing the position of the unit cell before and after forging.
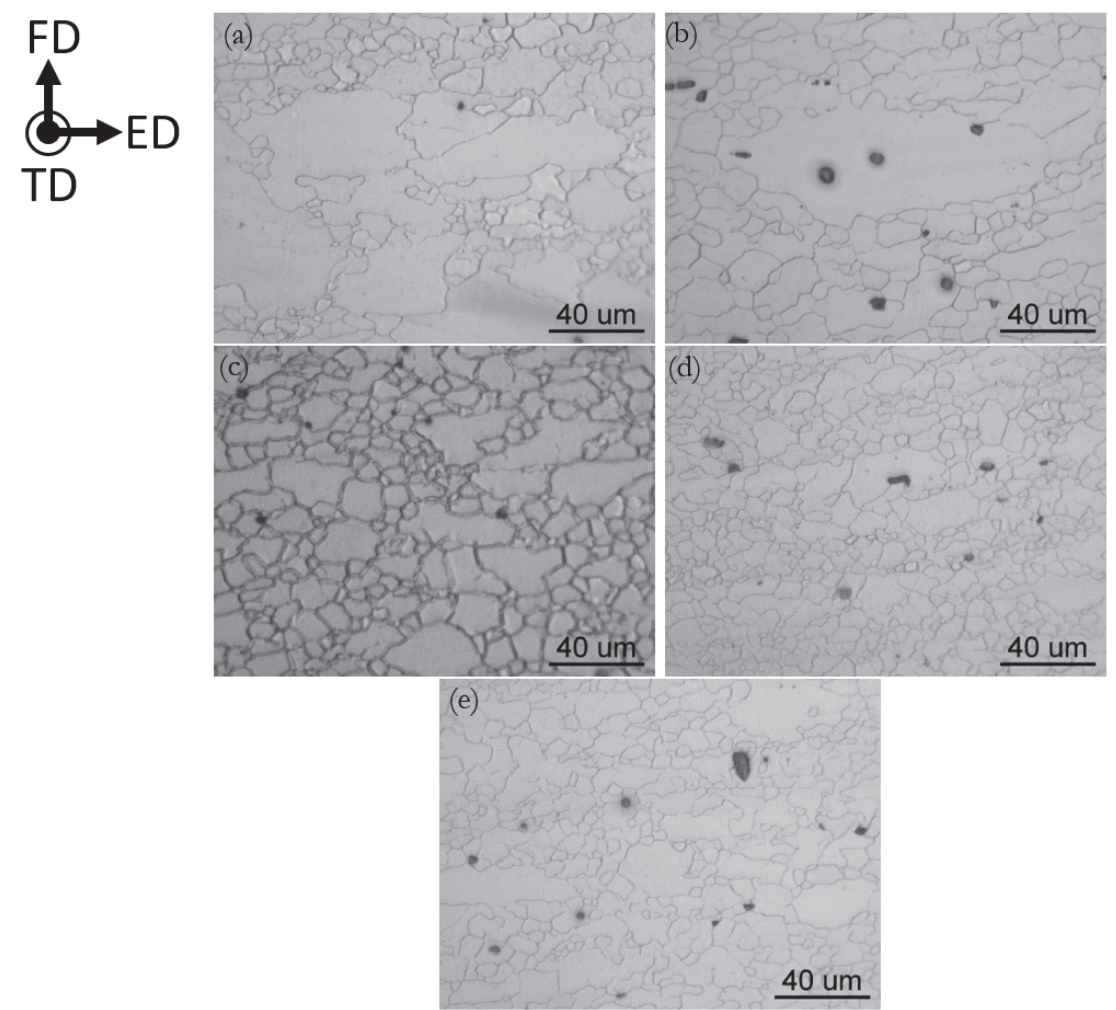

Figure 4: Typical optical microstructures of AZ31B extruded magnesium alloy forged at $3.9 \mathrm{~mm} / \mathrm{min}$ and various temperatures of (a) $\mathrm{S} 1-300^{\circ} \mathrm{C}$ (b) S2a $-400^{\circ} \mathrm{C}$ (c) S3 $-450^{\circ} \mathrm{C}$ and then $400^{\circ} \mathrm{C}$ and various rates of (d) S2b $-39 \mathrm{~mm} / \mathrm{min}$ and (e) $\mathrm{S} 2 \mathrm{c}-390 \mathrm{~mm} / \mathrm{min}$. 
This effect of forging on the basal texture is a modification of the predominant crystallographic orientation to be axissymmetric in the as-extruded billet to a planar orientation parallel to the direction of forging in all forging conditions. Important to note is that since the direction of forging was coincident to the c-axis orientation for the vertical (ED-RD) plane of crystals in the as-extruded billet, virtually no rotation of c-axis will occur in these crystals. However, crystals which lie in locations off this vertical plane of the initial billet will reorient their axis to be coincident with the direction of forging. The rotation of the c-axis in cases where the forging direction is perpendicular to the c-axis has been reported by several researchers in the literature [3,32, 45]. Previous work by Gryguc et al [46] done with axially forged AZ31B extruded billets show an obvious c-axis reorientation, with $\{10 \overline{1} 2\}$ extension twins being formed via a rotation of $\sim 86.3^{\circ}$ towards the loading direction, resulting in a reduction of yield stress. The orientation of the unit cell within the final forging is schematically shown in Fig. 3d with the basal plane of most unit cells being oriented normal to the forging direction. Wang et al. [47] had found that following significant plastic strain, most c-axis orientations which are favourable for twinning will re-orient them to the direction of forging. Furthermore, several researchers $[8-10,12,48]$ have also observed that the first pass of multidirectional forging also yields the largest modification to the texture, as the rotation of the c-axis to align with the direction of applied load and evolution of twin volume fraction are highest in the first forging step which agree well with the observations seen in the current study.
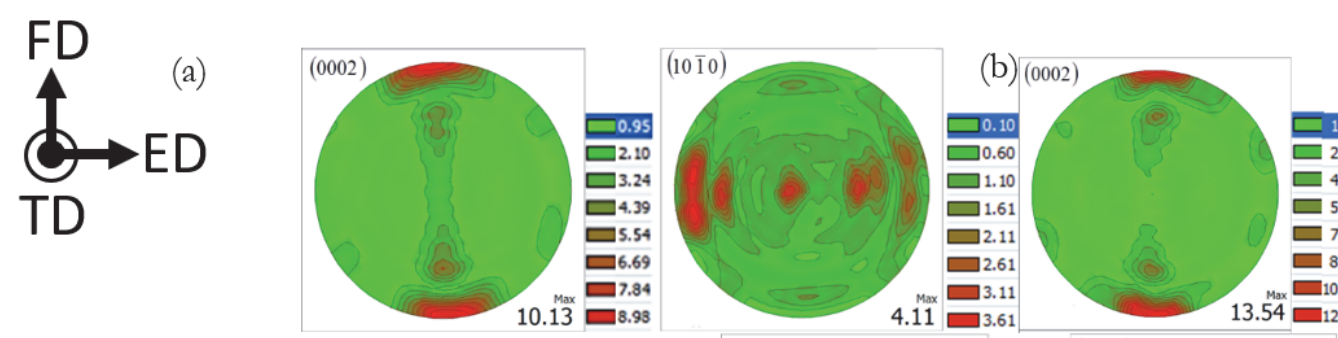

(c)

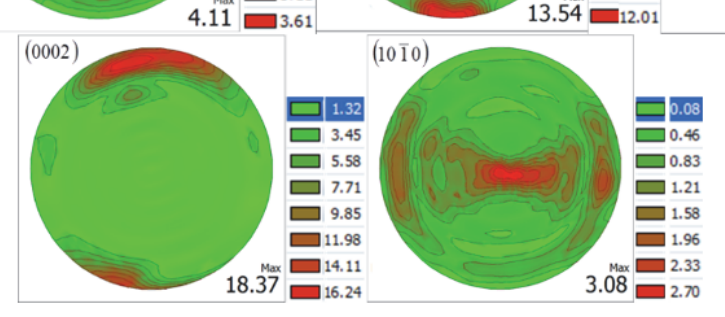

Figure 5: Sensitivity of texture to forging temperature: $(0002)$ and $(10 \overline{1} 0)$ pole figures obtained from the AZ31B extruded magnesium alloy forged at (a) $\mathrm{S} 1-300^{\circ} \mathrm{C}$, (b) $\mathrm{S} 2 \mathrm{a}-400^{\circ} \mathrm{C}$ and (c) $\mathrm{S} 3-450^{\circ} \mathrm{C}$ temperature for the speed of $3.9 \mathrm{~mm} / \mathrm{min}$.

(a)

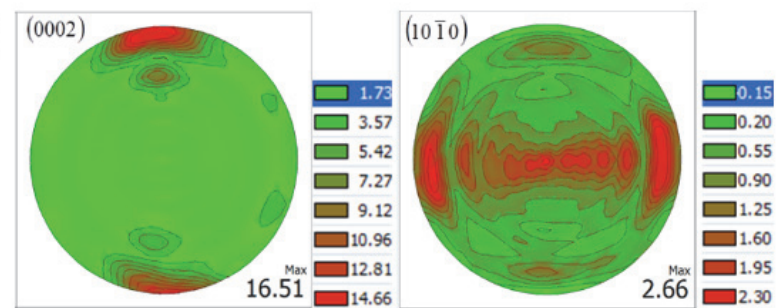

(b)

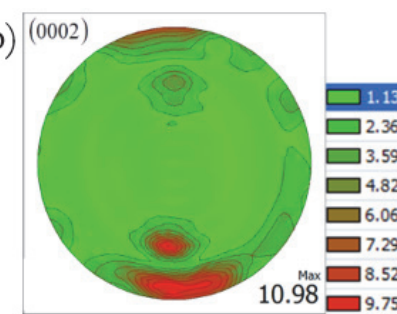

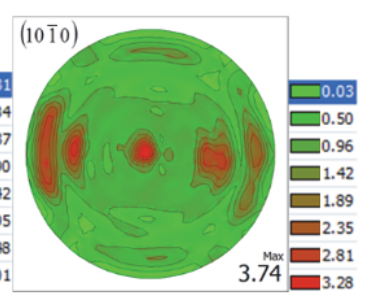

2.81
-3.28

.08
0.46
0.83
1.21
1.58
1.96
2.33
2.70

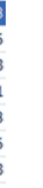


perpendicular to the direction of forging. In addition, there is also a moderate increase in the ultimate tensile stress in the material once forged. Both the yield and ultimate strengths as well as failure elongation exhibit a fairly weak sensitivity to strain rate (as illustrated by S2a, S2b and S2c). Fig. 7c and d illustrate the hardening behaviour for the investigated conditions. Sarker et al observed a hardening response that is characterized by 3 distinct stages for AM30 [50]. These three stages can be described as: an initial rapid decrease in strain hardening rate, followed by an inflection point and gradual increase in hardening rate, and finally a more moderate decrease in strain hardening rate until failure. All of the extruded and forged samples exhibit only two distinct hardening response stages which are similar to stages 1 and 3 described above, however no rate stabilization similar to stage 2 was observed. As described by Gryguc et al [46], the presence of the hardening stabilization or gradual rate increase in stage 2 is an indicator of the occurrence of twinning deformation whereas the absence of the stabilization zone is indicative of slip being the salient deformation mechanism. It can be seen in Fig. 7c that the transition between stage 1 and stage 3 hardening occurs in the as-extruded material more abruptly and at a lower true strain than in the forged material, regardless of the condition. Several researchers $[9,10,15]$ also observed very similar tensile hardening behaviour with increasing number of passes of multidirectional forging, supporting the observation that the dominant deformation mechanism in tension is slip, regardless of the texture intensity (or level of randomization present within the material).The compressive stress-strain curves shown in Fig. 7b show evidence of sigmoidal hardening behaviour for both the base material and all forged conditions. This is indicative of twinning deformation and a hardening response with three distinct stages. Wang et al. [47] observed a similar hardening behaviour in compression for AZ31B samples parallel to the extrusion direction, whereas normal to the extrusion direction, only stage 1 and 3 were evident. As shown in Fig. $7 \mathrm{~b}$, a similar trend to that which was observed in tension is also true in compression such that a significant increase in yield and moderate increase in ultimate strength were observed. However, the increase in compressive ductility is minimal once forged. Fig. $7 \mathrm{~d}$ shows the compressive hardening response for all investigated conditions, it is evident that three distinct hardening zones exist as discussed earlier. Stage 1 shows the initial rapid decrease in hardening rate to be virtually identical in all investigate conditions with the forged conditions tending towards a later transition to stage 2 due to their higher yield strength. In the as-extruded material, stage 2 shows clear evidence of rate stabilization indicative of twinning deformation, with a steady increase in hardening rate due to increasing twinning density to an eventual hardening rate saturation at $\sim 8 \%$ true strain. All of the forged conditions exhibit similar hardening behaviour with only slight differences in stage 2 behaviour. Firstly, the forged materials exhibit no true rate stabilization in stage 2, simply an exponentially increasing hardening rate to the same eventual hardening saturation as the as-extruded material. However, the onset of stage 2 hardening is characterized by a lower initial rate indicative of almost pure twinning in the post yield regime transitioning to mixed hardening between $5-8 \%$ strain as the refined microstructure of the forged material acts to modifying the mechanism for twin nucleation, growth and interaction. This observation is supported by the more intense basal texture in all of the forged conditions. Finally, both the tensile and compressive responses show greater sensitivity to temperature than they do to strain rate, and based upon this observation, it can be concluded that condition $\mathrm{S} 1\left(300^{\circ} \mathrm{C}\right)$ can be considered optimal in terms of monotonic properties. Additional to this, the yield asymmetry which is very pronounced in the as-extruded material decreases significantly once forged, with condition S1 showing the lowest asymmetry as can be seen in Fig. $7 \mathrm{f}$.

As discussed previously, the mechanical properties of magnesium alloy are significantly influenced by the texture, especially the orientation of the crystallographic c-axis relative to the loading direction of the material. It can be seen that in terms of both tensile and compressive monotonic responses, the base and forged materials all exhibit the same type of hardening behaviour (albeit the base materials hardening saturates sooner than in the as forged materials). Coupling this observation with the XRD results presented in Fig. 6 reinforce the conclusion that the improvement in mechanical properties can be attributed to the changes in both microstructure (grain refinement and homogeneity) and the modification of texture (from axisymmetric to planar HCP crystal orientation).

Fig. 8 shows the S-N curve obtained from both the as-extruded and forged specimens at different stress amplitudes. As seen in Fig. 8a, the samples forged at $400^{\circ} \mathrm{C}$ obtained significantly longer fatigue life in both the low and high cycle regime for the fixed stress amplitude, regardless of the forging speed. Fig. $8 \mathrm{~b}$ illustrates that at a fixed forging rate of $3.9 \mathrm{~mm} / \mathrm{min}$, the low cycle fatigue response is very similar regardless of the forging temperature. However, in the mid to high cycle regime, a forging temperature of $400^{\circ} \mathrm{C}$ yielded the longest life for this a forging speed of $3.9 \mathrm{~mm} / \mathrm{min}$. At $140 \mathrm{MPa}$ stress amplitude, the as-extruded alloy showed a fatigue life of $\sim 2.1 \times 10^{6}$ cycles while all forged conditions exhibited a higher number of cycles to failure, with the following forged conditions (S2a, S2b) exhibiting a life greater than 107 cycles. This is attributed to the forged material having a considerably larger elastic regime as compared to the as-extruded sample as discussed above. 
(a)
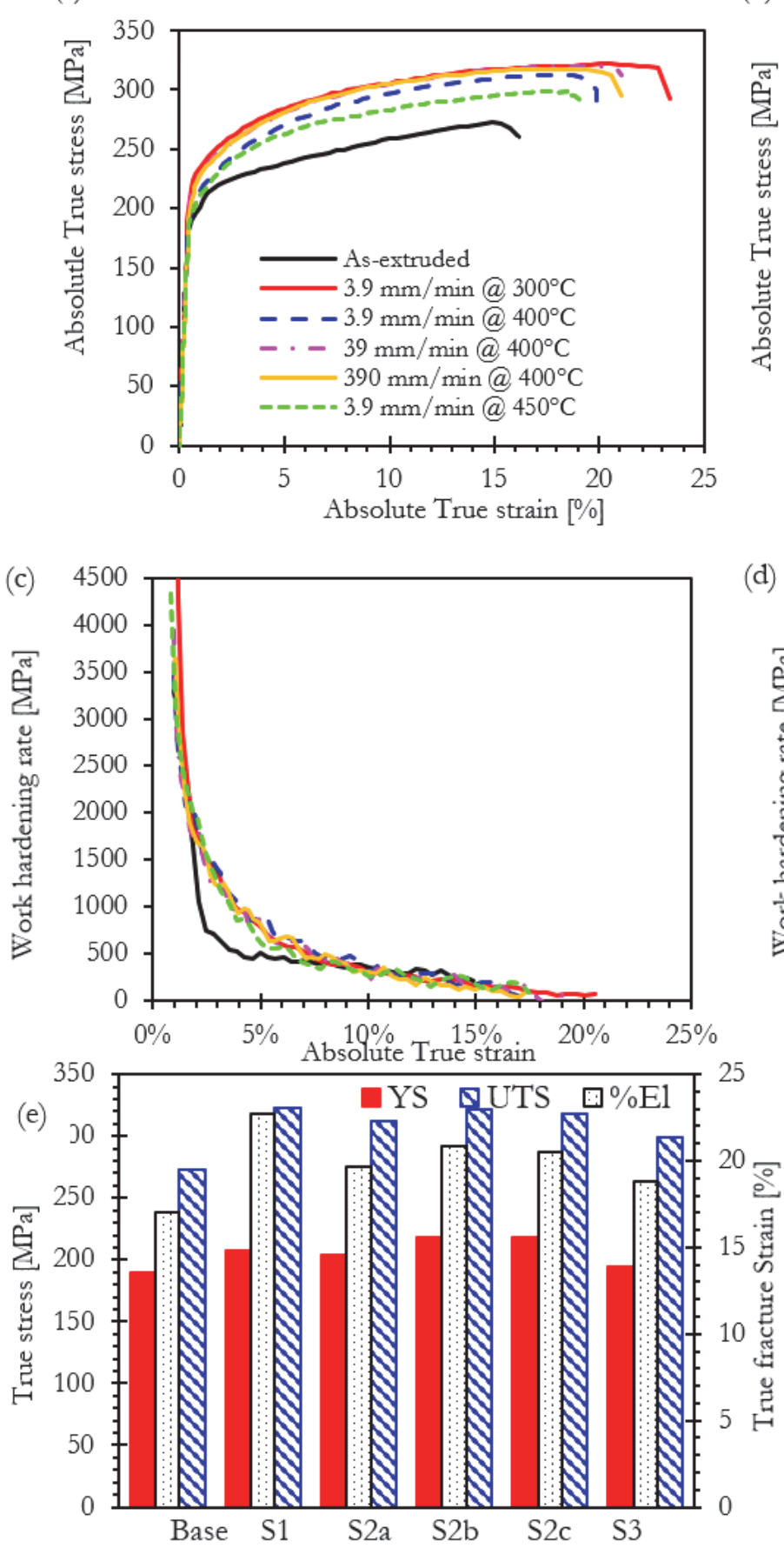

(b)

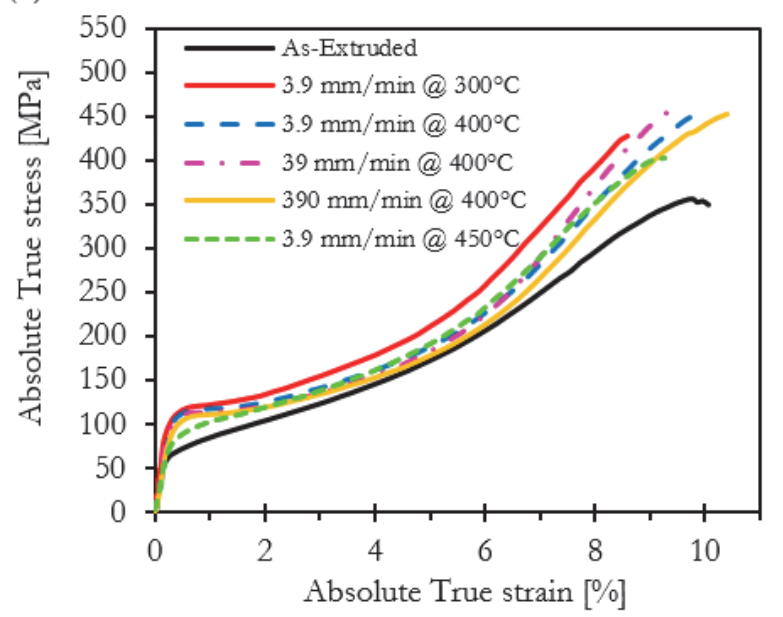

(d)

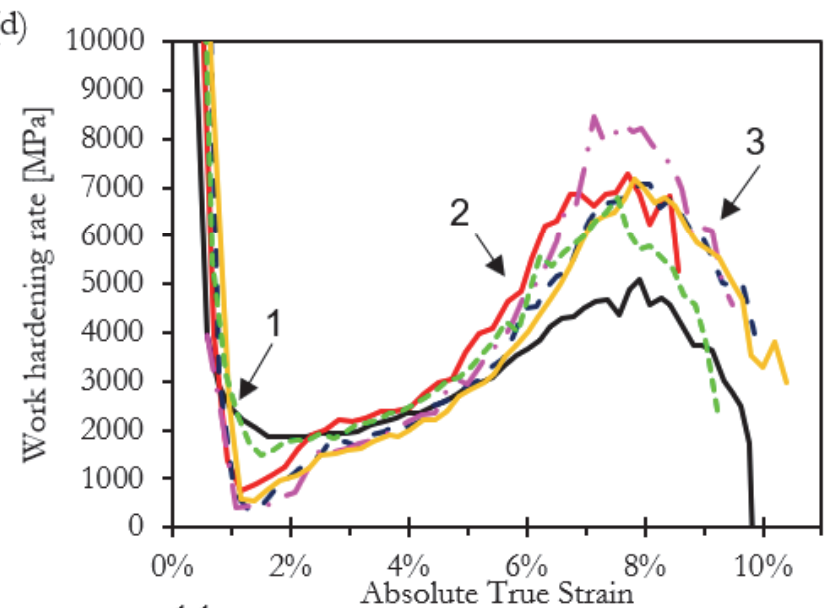

(f)

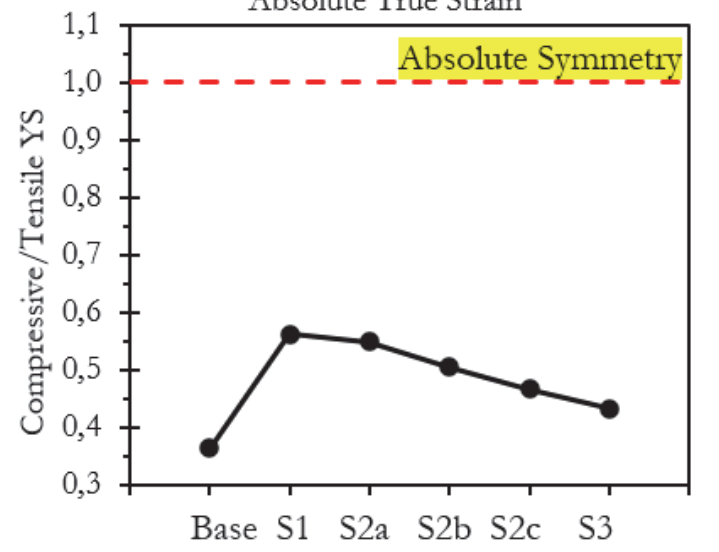

Figure 7: A comparison between base (as-extruded) and forged samples, (a) tensile and (b) compressive stress strain curves and respective $\mathrm{K}-\mathrm{M}$ plots (c) tensile (d) compressive, (e) tensile monotonic properties summary and (f) yield asymmetry ratio of the base and forged AZ31B magnesium alloy. 

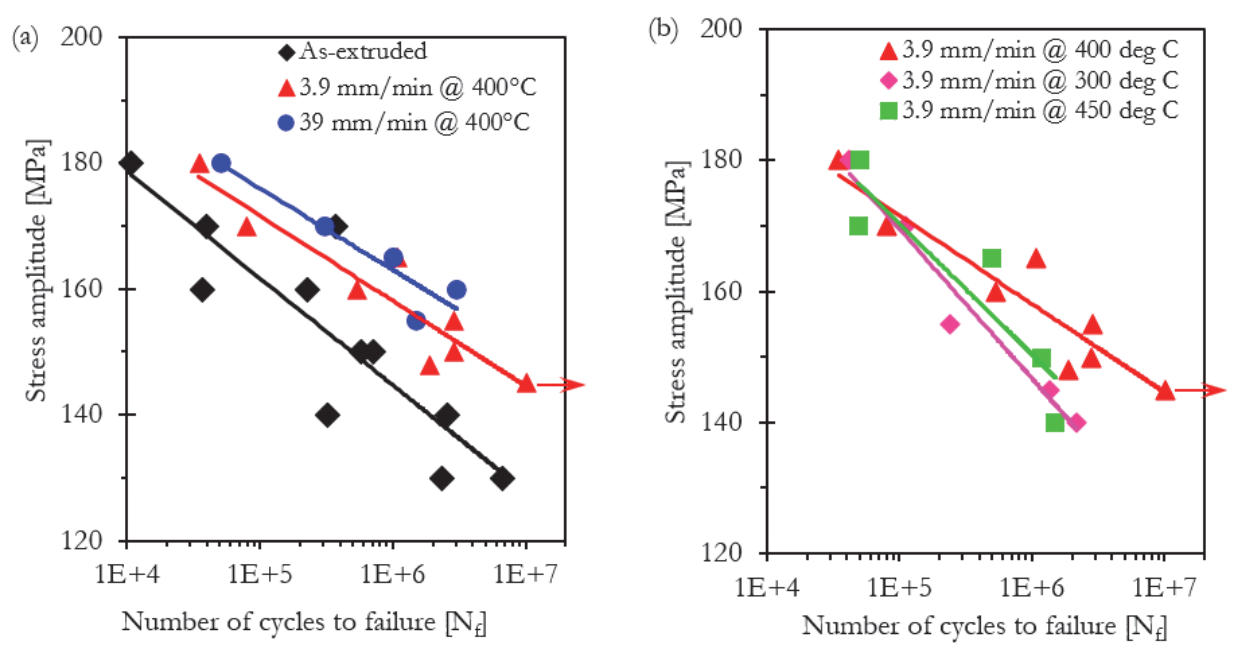

Figure 8: S-N Plot of the stress amplitudes of 130-180 MPa vs. number of cycles until failure for the AZ31B magnesium alloy in asextruded and radially forged at different rates and temperatures; (a) comparison between the as-extruded and forged at a fixed temperature of $400^{\circ} \mathrm{C}$ and rate of 3.9 and $39 \mathrm{~mm} / \mathrm{min}$, and (b) comparison with different temperatures of $300^{\circ} \mathrm{C}, 400^{\circ} \mathrm{C}$ and $450^{\circ} \mathrm{C}$ for a fixed rate of $3.9 \mathrm{~mm} / \mathrm{min}$.

\section{Fracture Mechanisms}

SEM images showing the macroscopic features of the fracture surface of the monotonic tensile specimens are illustrated in Fig. 9. The as-extruded condition Fig. 9(a) exhibited a vigorously cleaved surface with facets of varying orientation and size. All forged samples Fig. 9(b - e) exhibited very similar fracture surface morphology regardless of the forging condition. The morphology for the as-extruded material is characterized by a significantly faceted and cleaved surface which shows evidence of twinning deformation for a large proportion of the area. In contrast to the as-extruded condition, the forged samples had features which were dimple-like in nature agreeing well with the observed increase in ductility and evidence of macroscopic plasticity. Fig. 10 shows higher magnification images of the monotonic tensile fracture surface for the as-extruded Fig. 9(a) and various forged conditions $(\mathrm{b}-\mathrm{e})$. The as-extruded fracture surface is characterized by a lamellar morphology with many parallel groupings of lamella with varying orientations. The interfaces of these lamella are characterized by tear ridges which are the boundary between adjacent terraces of varying elevation. The fracture surface of the forged material is characterized by many shallow dimples with tear ridges that seem to be predominantly at $45^{\circ}$ directions to either the lateral or longitudinal directions on the image (which corresponds to a $45^{\circ}$ angle relative to the forging direction/c-axis direction). The presence of a vigorously dimpled surface morphology is the main characteristic which differentiates the forged from the as-extruded conditions. It is well known that that the depth of the dimples is an qualitative indicator of ductility with deeper dimples corresponding to more plasticity [52]. This agrees well with the more ductile tensile monotonic response of the material once forged. Wang et al [52] investigated the tensile fracture surface morphology of extruded AZ80 specimens which underwent Equal Channel Angular Pressing (ECAP) and observed that the fracture surface varied only slightly before and after ECAP, and did not vary with up to 4 subsequent passes of further ECAP deformation, other researchers [53, 54] have also had analogous findings.

SEM images showing the macroscopic features of the fracture surface of the fatigue specimens are shown in Fig. 11. All samples exhibited fatigue crack initiation (FCI) at the surface of the specimen. The as-extruded material (Fig. 11c) exhibits a fracture surface with a severely faceted morphology with substantial cleavage like terraces and widespread macroscopic striations of varying orientations. The propagation zone is also comparatively rough relative to the forged sample (Fig. 11d). In contrast, the forged sample exhibited a distinct FCI with radially branching ratchet marks and a large propagation zone which is much flatter and more stable than the as-extruded condition. The final fracture zone is opposite to the FCI location indicating a stable crack propagation in a direction which is approximately perpendicular to the initial fatigue crack initiation site as is typical with fully reversed zero mean offset rotating bending testing. A magnified view of the propagation zone on the fracture surface morphology is shown in Fig. 12 (a, c). It can be seen that for the as-extruded material (Fig. 12a) the general direction of fatigue striations (FS) is in the diagonal direction on the image (which corresponds to a $\sim 45^{\circ}$ angle to the crack propagation direction). A distinct herringbone pattern is also present with the apex of fatigue striations occurring on what appears to be grain boundaries. Yin et al [27] observed similar twin lamella in AZ31 extrusion during strain controlled fatigue testing. Zhang et al [53] denoted the "apex" or interface of parallel groupings of striations as secondary cracks in welded AZ31B plate material during stress controlled fatigue testing. The forged condition S2a (Fig. 12c) exhibits fatigue striations which, in general, branch in directions which are radial to the location of FCI (longitudinally in the image). 
The final fracture zone surface morphology is shown in Fig. 12(b, d). The as-extruded material Fig. 12(b) shows some evidence of ductility as well as an intergranular fracture morphology with a faceted structure. The forged sample Fig. 12(d) showed much more evidence of ductility with a very pronounced dimpled surface morphology and terrace like structure supporting the observation of more plastic fracture behaviour.
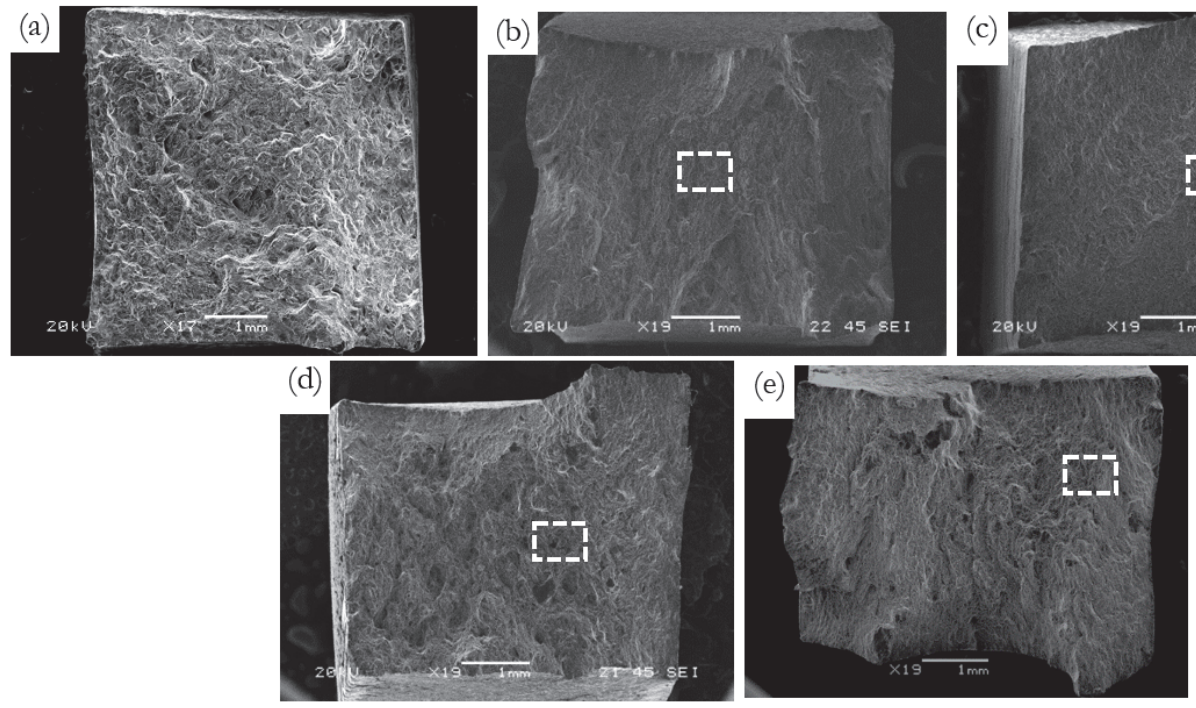

Figure 9: SEM micrographs showing the overall tensile fracture surface of the AZ31B extruded samples (a); forged at rate of $3.9 \mathrm{~mm} / \mathrm{min}$ and a temperature of (b) $300^{\circ} \mathrm{C}$ (c) $400^{\circ} \mathrm{C}$ and (d) $450^{\circ} \mathrm{C}$, and (e) forging rate of $39 \mathrm{~mm} / \mathrm{min}$ at a temperature of $400^{\circ} \mathrm{C}$ Note: the enclosed areas are magnified in Fig. 10.

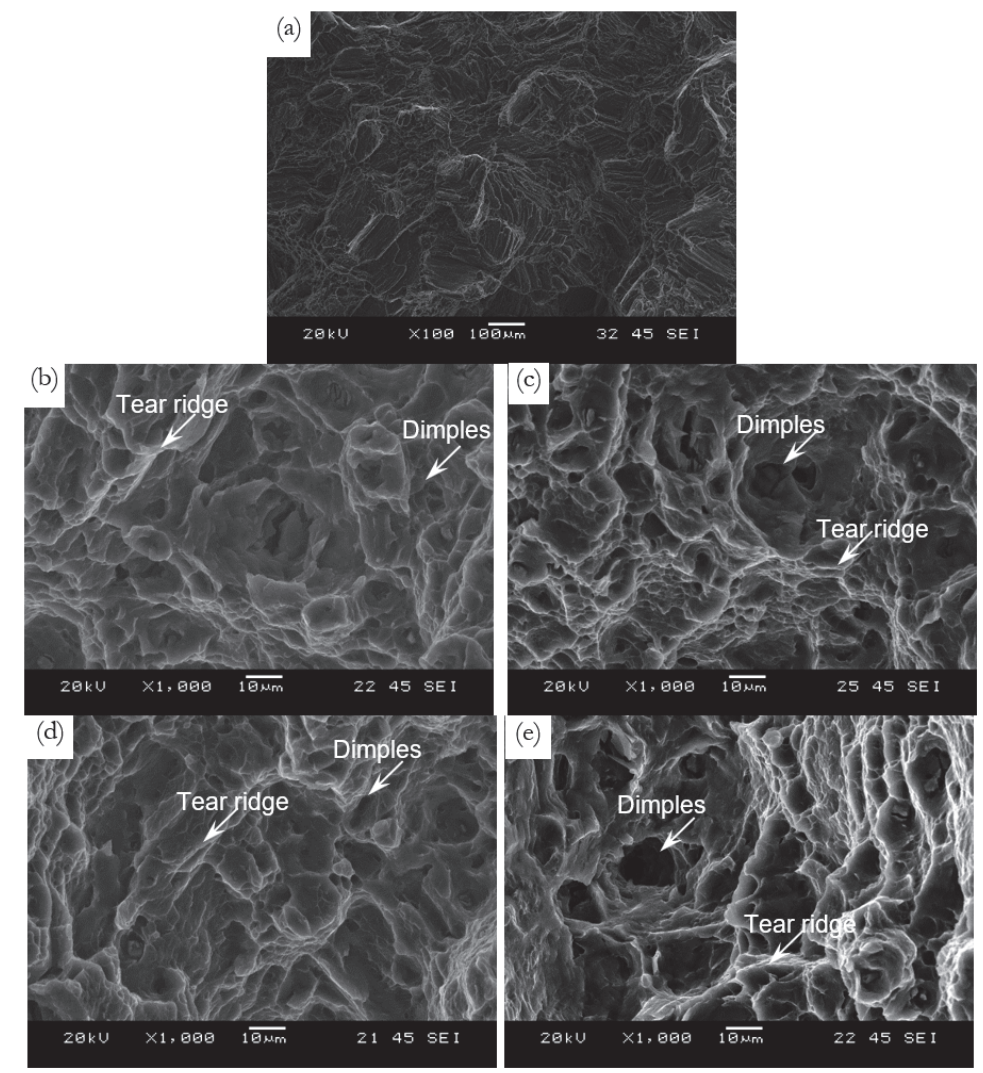

Figure 10: The corresponding SEM micrographs showing morphology (enclosed in Fig. 9) of the tensile fracture surface of the AZ31B extruded samples (a); forged at rate of $3.9 \mathrm{~mm} / \mathrm{min}$ and a temperature of (b) $300^{\circ} \mathrm{C}$ (c) $400^{\circ} \mathrm{C}$ and (d) $450^{\circ} \mathrm{C}$, and (e) forging rate of $39 \mathrm{~mm} / \mathrm{min}$ at a temperature of $400^{\circ} \mathrm{C}$. 

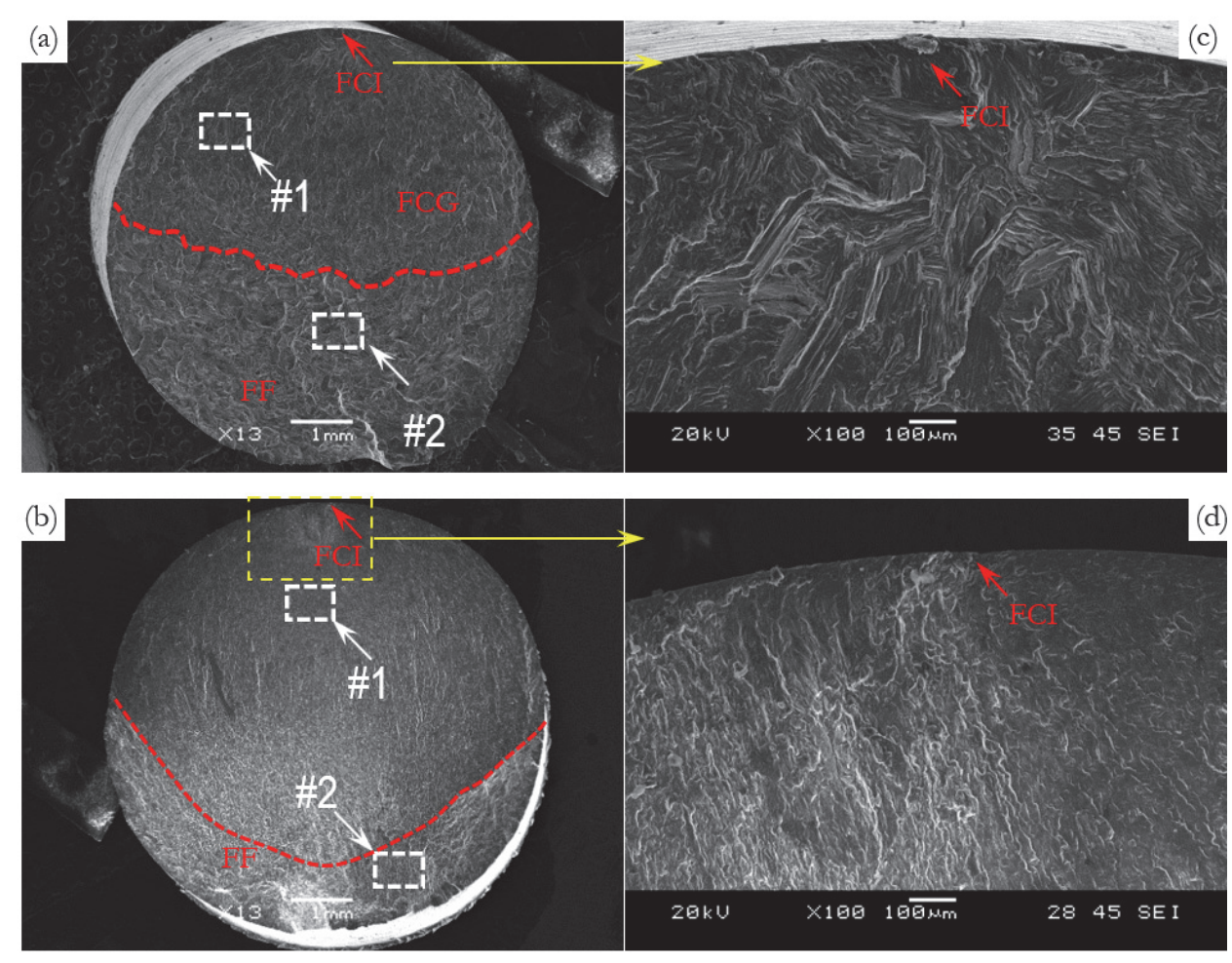

Figure 11: SEM images of fatigue fracture surfaces of the samples tested at total stress amplitude of 150 MPa showing an overall view for the AZ31B magnesium alloy in (a) as-extruded condition and (b) forged at the rate of $3.9 \mathrm{~mm} / \mathrm{min}$ at $400^{\circ} \mathrm{C}$ temperature (S2a), and the corresponding fatigue crack initiation sites at higher magnifications; (c) as-extruded. (d) forged condition S2a. Here, yellow boxes and red arrows are showing the position of fatigue crack initiation (FCI) sites while red dashed line separated the fatigue crack growth/propagation (FCG) area and final fracture (FF).
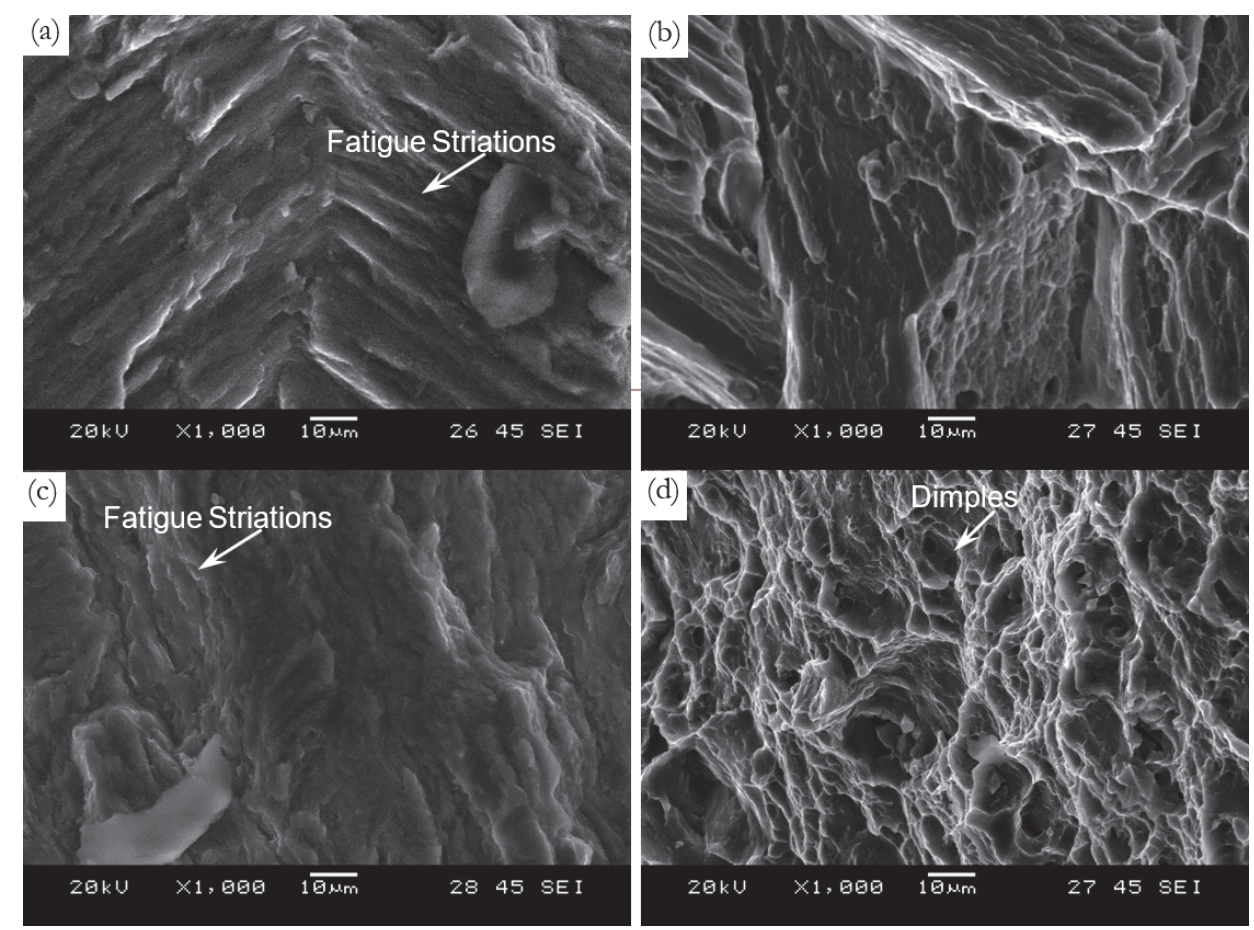

Figure 12: The magnified view of SEM micrographs showing morphology of the fatigue fracture surface of the AZ31B extruded (a, b) and forged at temperature of $400^{\circ} \mathrm{C}$ for the rate of $3.9 \mathrm{~mm} / \mathrm{min}(\mathrm{c}, \mathrm{d})$ in the cracks propagation zone $(\mathrm{a}, \mathrm{c})$ and final fracture zone $(\mathrm{b}$, d) as indicated in Fig. 11 with locations $1 \& 2$. 


\section{CONCLUSIONS}

he tensile and fatigue behavior in the extrusion direction of as-extruded and forged AZ31B magnesium alloy were investigated. On the basis of the microstructure, stress-strain response characteristics and stress-controlled fatigue behavior, the following conclusions can be drawn:

1. The as-extruded condition exhibited a significant bi-modal grain structure with average grain size of $32.5 \mu \mathrm{m}$ while the forged sample shows smaller, equi-axed grains with average grain size of about $11.7 \mu \mathrm{m}$.

2. The thermomechanical process of open die forging recrystallizes the microstructure and modifies the axisymmetric basal texture of the extruded billed to be intense basal texture in the plane of the forged specimen with the crystallographic c-axis reorienting itself to be parallel with the forging direction.

3. After forging, both the strength and ductility of the alloy were improved, predominantly resulting from the more refined grain structure. It was observed that AZ31B alloy had a yield strength and failure elongation of about 189 $\mathrm{MPa}$ and $17 \%$ in as-extruded state while in the forged condition these properties improved to $218 \mathrm{MPa}$ and $21 \%$ respectively.

4. The cyclic behaviour also showed an appreciable improvement in performance, i.e. longer fatigue life with an increase of $22 \mathrm{MPa}$ in fatigue strength at $10^{7}$ cycles being typical of the forged vs. as-extruded material.

5. The monotonic and fatigue responses exhibited a higher sensitivity to forging temperature rather than deformation rate. In general, the strength is inversely correlated to the forging temperature and positively correlated to rate.

6. The fracture surfaces of all samples were characterized by a terrace-like faceted morphology with an intergranular fracture path in the as-extruded condition, whereas the forged conditions exhibited a much more dimple-like fracture surface and transgranular fracture path indicative of more plasticity.

\section{ACKNOWLEDGEMENT}

he financial support of the Natural Sciences and Engineering Research Council of Canada (NSERC) through the Automotive Partnership Canada (APC) under APCPJ 459269-13 grant with contributions from Multimatic Technical Centre, Ford Motor Company, and Centerline Windsor are acknowledged. The authors would also like to acknowledge J. McKinley from CanmetMATERIALS for forging trials.

\section{REFERENCES}

[1] Skszek, T.W., Zaluzec, M., Conklin, J., Wagner, D. (2016). MMLV : Project Overview, SAE Int., (10.4271/2015-010407), DOI: 10.4271/2015-01-0407.

[2] Chen, X., Conklin, J.L., Carpenter, R.M., Wallace, J., Flanigan, C., Wagner, D.A., Kiridena, V., Betrancourt, S., Logsdon, J. (2015). MMLV : Chassis Design and Component Testing, SAE Int., (10.4271/2015-01-1237), DOI: $10.4271 / 2015-01-1237$.

[3] Sarker, D., Friedman, J., Chen, D.L. (2014). Influence of pre-strain on de-twinning activity in an extruded AM30 magnesium alloy, Mater. Sci. Eng. A, 605, pp. 73-79, DOI: 10.1016/j.msea.2014.03.046.

[4] Pan, H., Ren, Y., Fu, H., Zhao, H., Wang, L., Meng, X., Qin, G. (2016). Recent developments in rare-earth free wrought magnesium alloys having high strength: A review, J. Alloys Compd., 663, pp. 321-331, DOI: $10.1016 /$ j.jallcom.2015.12.057.

[5] Al-Samman, T., Gottstein, G. (2008). Dynamic recrystallization during high temperature deformation of magnesium, Mater. Sci. Eng. A, 490(1-2), pp. 411-20, DOI: 10.1016/j.msea.2008.02.004.

[6] Yan, Z., Wang, D., Wang, W., Zhou, J., He, X., Dong, P., Zhang, H., Sun, L. (2018). Ratcheting strain and microstructure evolution of AZ31B magnesium alloy under a tensile-tensile cyclic loading, Materials (Basel), 11(4), DOI: $10.3390 / \mathrm{ma1} 1040513$.

[7] Salandari-Rabori, A., Zarei-Hanzaki, A., Fatemi, S.M., Ghambari, M., Moghaddam, M. (2017). Microstructure and superior mechanical properties of a multi-axially forged WE magnesium alloy, J. Alloys Compd., 693, pp. 406-413, DOI: 10.1016/j.jallcom.2016.09.198.

[8] Salandari-Rabori, A., Zarei-Hanzaki, A., Abedi, H.R., Lecomte, J.S., Khatami-Hamedani, H. (2018). Micro and macro texture evolution during multiaxial forging of a WE43 magnesium alloy, J. Alloys Compd., 739, pp. 249-259, 
DOI: $10.1016 /$ j.jallcom.2017.12.181.

[9] Biswas, S., Suwas, S. (2012). Evolution of sub-micron grain size and weak texture in magnesium alloy Mg-3Al-0.4Mn by a modified multi-axial forging process, Scr. Mater., 66(2), pp. 89-92, DOI: 10.1016/j.scriptamat.2011.10.008.

[10] Ramezani, S.M., Zarei-Hanzaki, A., Abedi, H.R., Salandari-Rabori, A., Minarik, P. (2019). Achievement of fine-grained bimodal microstructures and superior mechanical properties in a multi-axially forged GWZ magnesium alloy containing LPSO structures, J. Alloys Compd., 793, pp. 134-145, DOI: 10.1016/j.jallcom.2019.04.158.

[11] Miura, H., Maruoka, T., Jonas, J.J. (2013). Effect of ageing on microstructure and mechanical properties of a multidirectionally forged Mg-6Al-1Zn alloy, Mater. Sci. Eng. A, 563, pp. 53-59, DOI: 10.1016/j.msea.2012.11.021.

[12] Asqardoust, S., Zarei Hanzaki, A., Abedi, H.R., Krajnak, T., Minárik, P. (2017). Enhancing the strength and ductility in accumulative back extruded WE43 magnesium alloy through achieving bimodal grain size distribution and texture weakening, Mater. Sci. Eng. A, 698(April), pp. 218-229, DOI: 10.1016/j.msea.2017.04.098.

[13] Liu, J., Wang, Q., Zhou, H., Guo, W., Jiang, H., Ding, W. (2015).Effect of Cyclic Closed-Die Forging on Microstructure and Mechanical Properties of NZ30K Magnesium Alloy. The 10th International Conference on Magnesium Alloys and Their Applications Oct., pp. 473-477.

[14] Cai, C., LingHui, S., XingHao, D., BaoLin, W. (2017). Enhanced mechanical property of AZ31B magnesium alloy processed by multi-directional forging method, Mater. Charact., 131(May), pp. 72-77, DOI: 10.1016/j.matchar.2017.05.010.

[15] Cao, F., Zhang, J., Ding, X., Xue, G., Liu, S., Sun, C., Su, R., Teng, X. (2019). Mechanical properties and microstructural evolution in a superlight $\mathrm{Mg}-6.4 \mathrm{Li}-3.6 \mathrm{Zn}-0.37 \mathrm{Al}-0.36 \mathrm{Y}$ alloy processed by multidirectional forging and rolling, Mater. Sci. Eng. A, 760(June), pp. 377-393, DOI: 10.1016/j.msea.2019.06.009.

[16] Zhou, X., Zhang, J., Chen, X., Zhang, X., Li, M. (2019). Fabrication of high-strength AZ80 alloys via multidirectional forging in air with no need of ageing treatment, J. Alloys Compd., 787, pp. 551-559, DOI: $10.1016 /$ j.jallcom.2019.02.133.

[17] Miura, H., Matsumoto, K., Kobayashi, M. (2015). Multi-Directional Forging of AZ61Mg Alloy Using Die under Decreasing Temperature Conditions, (7), pp. 468-472.

[18] Yang, H.J., An, X.H., Shao, X.H., Yang, X.M., Li, S.X., Wu, S.D., Zhang, Z.F. (2011). Enhancing strength and ductility of Mg-12Gd-3Y-0.5Zr alloy by forming a bi-ultrafine microstructure, Mater. Sci. Eng. A, 528(13-14), pp. 4300-4311, DOI: $10.1016 /$ j.msea.2011.02.041.

[19] Madaj, M., Greger, M., Karas, V. (2015). Magnesium-alloy die forgings for automotive applications, Mater. Tehnol., 49(2), pp. 267-273, DOI: 10.17222/mit.2013.174.

[20] Kobold, D., Pepelnjak, T., Gantar, G., Kuzman, K. (2010). Analysis of deformation characteristics of magnesium AZ80 wrought alloy under hot conditions, Stroj. Vestnik/Journal Mech. Eng., 56(12), pp. 823-832.

[21] Kurz, G., Clauw, B., Sillekens, W.H., Letzig, D., Manufacturing, P. (2009). Die Forging of the Alloys Az80 and Zk60, Mater. Soc. Annu. Meet., pp. 197-202.

[22] Nový, F., Janeček, M., Škorik, V., Muller, J., Wagner, L. (2009). Very high cycle fatigue behaviour of as-extruded AZ31, AZ80, and ZK60 magnesium alloys, Int. J. Mater. Res., 100(3), pp. 288-291, DOI: 10.3139/146.110043.

[23] Begum, S., Chen, D.L., Xu, S., Luo, A.A. (2009). Low cycle fatigue properties of an extruded AZ31 magnesium alloy, Int. J. Fatigue, 31(4), pp. 726-735, DOI: 10.1016/j.ijfatigue.2008.03.009.

[24] Gryguc, A., Shaha, S.K., Behravesh, S.B., Jahed, H., Wells, M., Williams, B., Su, X. (2017). Monotonic and cyclic behaviour of cast and cast-forged AZ80 Mg, Int. J. Fatigue, 104, pp. 136-149, DOI: 10.1016/j.ijfatigue.2017.06.038.

[25] Gryguc, A., Behravesh, S.B., Shaha, S.K., Jahed, H., Wells, M., Williams, B., Su, X. (2018). Low-cycle fatigue characterization and texture induced ratcheting behaviour of forged AZ80 Mg alloys, Int. J. Fatigue, 116, pp. 429-438, DOI: $10.1016 /$ j.ijfatigue.2018.06.028.

[26] Somekawa, H., Maruyama, N., Hiromoto, S., Yamamoto, A., Mukai, T. (2008). Fatigue behaviors and microstructures in an extruded Mg-Al-Zn alloy, Mater. Trans., 49(3), pp. 681-684, DOI: 10.2320/matertrans.MRP2007292.

[27] Yin, S.M., Yang, F., Yang, X.M., Wu, S.D., Li, S.X., Li, G.Y. (2008). The role of twinning-detwinning on fatigue fracture morphology of Mg-3\%Al-1\%Zn alloy, Mater. Sci. Eng. A, 494(1-2), pp. 397-400, DOI: 10.1016/j.msea.2008.04.056.

[28] Xu, D.K., Liu, L., Xu, Y.B., Han, E.H. (2007). The crack initiation mechanism of the forged Mg-Zn-Y-Zr alloy in the super-long fatigue life regime, Scr. Mater., 56(1), pp. 1-4, DOI: 10.1016/j.scriptamat.2006.09.006.

[29] Kalatehmollaei, E., Mahmoudi-Asl, H., Jahed, H. (2014). An asymmetric elastic-plastic analysis of the load-controlled rotating bending test and its application in the fatigue life estimation of wrought magnesium AZ31B, Int. J. Fatigue, 64, pp. 33-41, DOI: 10.1016/j.ijfatigue.2014.02.012.

[30] Bahareh Marzbanrad, Ehsan Toyserkani, H.J. (2015). Applications of Fiber Bragg Grating Sensors To Strain Measurements of Az31B Extrusion in Rotating Bending Cyclic Tests, Proc. 25th CANCAM. 
[31] Gryguc, A., Behravesh, S.B., Jahed, H., Wells, M., Williams, B., Su, X. (2020). Multiaxial Fatigue and Cracking Orientation of Forged AZ80 Magnesium Alloy, Procedia Struct. Integr., 25 (1st Virtual Conference on Structural Integrity-VCSI1), pp. 486-495, DOI: 10.1016/j.prostr.2020.04.055.

[32] Albinmousa, J., Jahed, H., Lambert, S. (2011). Cyclic axial and cyclic torsional behaviour of extruded AZ31B magnesium alloy, Int. J. Fatigue, 33(11), pp. 1403-1416, DOI: 10.1016/j.ijfatigue.2011.04.012.

[33] Albinmousa, J., Jahed, H. (2014). Multiaxial effects on LCF behaviour and fatigue failure of AZ31B magnesium extrusion, Int. J. Fatigue, 67, pp. 103-116, DOI: 10.1016/j.ijfatigue.2014.01.025.

[34] Albinmousa, J., Jahed, H., Lambert, S. (2010). An Energy-Based Fatigue Model for Wrought Magnesium Alloy under Multiaxial Load, Ninth Int. Conf. Multiaxial Fatigue Fract., pp. 471-478.

[35] Jahed, H., Albinmousa, J. (2014). Multiaxial behaviour of wrought magnesium alloys - A review and suitability of energybased fatigue life model, Theor. Appl. Fract. Mech., 73, pp. 97-108, DOI: 10.1016/j.tafmec.2014.08.004.

[36] Tokaji, K., Kamakura, M., Ishiizumi, Y., Hasegawa, N. (2004). Fatigue behaviour and fracture mechanism of a rolled AZ31 magnesium alloy, Int. J. Fatigue, 26(11), pp. 1217-1224, DOI: 10.1016/j.ijfatigue.2004.03.015.

[37] Morita, S., Ohno, N., Tamai, F., Kawakami, Y. (2010). Fatigue properties of rolled AZ31B magnesium alloy plate, Trans. Nonferrous Met. Soc. China (English Ed., 20(SUPPL. 2), pp. 1-5, DOI: 10.1016/S1003-6326(10)60531-6.

[38] Albinmousa, J., Jahed, H., Lambert, S. (2011). Cyclic behaviour of wrought magnesium alloy under multiaxial load, Int. J. Fatigue, 33(8), pp. 1127-1139, DOI: 10.1016/j.ijfatigue.2011.01.009.

[39] Gryguć, A., Behravesh, S.B., Shaha, S.K., Jahed, H., Wells, M., Williams, B., Su, X. (2019). Multiaxial cyclic behaviour of extruded and forged AZ80 Mg alloy, Int. J. Fatigue, 127, pp. 324-337, DOI: 10.1016/j.ijfatigue.2019.06.015.

[40] Gryguć, A., Karparvarfard, S.M.H., Roostaei, A., Toscano, D., Shaha, S., Behravesh, B., Jahed, H. (2020).On the Load Multiaxiality Effect on the Cyclic Behaviour of Magnesium Alloys. Magnesium Technology 2020, pp. 151-159.

[41] Gryguc, A., Behravesh, S.B., Jahed, H., Wells, M., Williams, B., Su, X. (2020). Multiaxial Fatigue and Cracking Orientation of Forged AZ80 Magnesium Alloy, Procedia Struct. Integr., (1st Virtual Conference on Structural IntegrityVCSI1).

[42] Mohamad, S., Karparvarfard, H., Behravesh, S.B., Kumar, S. (2019). On the phase angle role in the shear response of ZK60 Mg alloys under multiaxial fatigue, 08005, pp. 1-9.

[43] Wong, T.W., Hadadzadeh, A., Wells, M.A. (2018). High temperature deformation behavior of extruded AZ31B magnesium alloy, J. Mater. Process. Technol., 251(March 2017), pp. 360-368, DOI: 10.1016/j.jmatprotec.2017.09.006.

[44] Jamali, A., Mahmudi, R. (2019). Evolution of microstructure, texture, and mechanical properties in a multi-directionally forged ZK60 Mg alloy, Mater. Sci. Eng. A, 752(February), pp. 55-62, DOI: 10.1016/j.msea.2019.02.095.

[45] Sarker, D., Chen, D.L. (2013). Texture transformation in an extruded magnesium alloy under pressure, Mater. Sci. Eng. A, 582, pp. 63-67, DOI: 10.1016/j.msea.2013.06.048.

[46] Gryguc, A., Shaha, S.K., Jahed, H., Wells, M., Williams, B., McKinley, J. (2016). Tensile and fatigue behaviour of asforged AZ31B extrusion, Frat. Ed Integrita Strutt., 10(38), pp. 251-258, DOI: 10.3221/IGF-ESIS.38.34.

[47] Wang, B., Xin, R., Huang, G., Liu, Q. (2012). Effect of crystal orientation on the mechanical properties and strain hardening behavior of magnesium alloy AZ31 during uniaxial compression, Mater. Sci. Eng. A, 534, pp. 588-593, DOI: $10.1016 /$ j.msea.2011.12.013.

[48] Shah, S.S.A., Wu, D., Chen, R.S., Song, G.S. (2019). Static recrystallization behavior of multi-directional impact forged Mg-Gd-Y-Zr alloy, J. Alloys Compd., 805, pp. 189-197, DOI: 10.1016/j.jallcom.2019.07.086.

[49] Gryguc, A., Shaha, S.K., Behravesh, S.B., Jahed, H., Wells, M., Williams, B. (2017). Compression Behaviour of SemiClosed Die Forged AZ80 Extrusion, Charact. Miner. Met. Mater., pp. 361-369, DOI: 10.1007/978-3-319-51382-9_39.

[50] Gryguc, A., Jahed, H., Williams, B., McKinley, J. (2015). Magforge - Mechanical behaviour of forged AZ31B extruded magnesium in monotonic compression, Mater. Sci. Forum, 828-829, pp. 291-297, DOI: 10.4028/www.scientific.net/MSF.828-829.291.

[51] Sarker, D., Chen, D.L. (2012). Detwinning and strain hardening of an extruded magnesium alloy during compression, Scr. Mater., 67(2), pp. 165-168, DOI: 10.1016/j.scriptamat.2012.04.007.

[52] Wang, L., Mostaed, E., Cao, X., Huang, G., Fabrizi, A., Bonollo, F., Chi, C., Vedani, M. (2016). Effects of texture and grain size on mechanical properties of AZ80 magnesium alloys at lower temperatures, Mater. Des., 89, pp. 1-8, DOI: $10.1016 /$ j.matdes.2015.09.153.

[53] Kang, H.T., Ostrom, T. (2008). Mechanical behavior of cast and forged magnesium alloys and their microstructures, Mater. Sci. Eng. A, 490(1-2), pp. 52-6, DOI: 10.1016/j.msea.2008.02.030.

[54] Wang, S.D., Xu, D.K., Wang, B.J., Han, E.H., Dong, C. (2015). Effect of solution treatment on the fatigue behavior of an as-forged Mg-Zn-Y-Zr alloy, Mater. Des., 84(April), pp. 185-93, DOI: 10.1016/j.matdes.2015.06.109. 